\title{
Responses of plasma concentrations of A type natriuretic peptide and $B$ type natriuretic peptide to alacepril, an angiotensin-converting enzyme inhibitor, in patients with congestive heart failure
}

Michihiro Yoshimura, Hirofumi Yasue, Hidenori Tanaka, Koichi Kikuta, Hitoshi Sumida, Hideji Kato, Michihisa Jougasaki, Kazuwa Nakao

\begin{abstract}
Background-Plasma concentrations of A type or atrial natriuretic peptide (ANP) and $B$ type or brain natriuretic peptide (BNP) are increased in patients with congestive heart failure (CHF).

Objective-To examine the haemodynamic and hormonal responses, especially of ANP and BNP, to oral administration of an angiotensin-converting enzyme (ACE) inhibitor in patients with $\mathrm{CHF}$ and in controls.

Patients-12 patients with CHF and 11 controls.

Methods-Haemodynamic variables and plasma concentrations of ANP, BNP, and other hormones were serially measured for 24 hours after alacepril $(37.5 \mathrm{mg}$ ) was given by mouth.
\end{abstract}

Results-Pulmonary capillary wedge pressure and systemic vascular resistance decreased significantly in both groups. The cardiac index increased only in the CHF group. In patients with CHF pulmonary capillary wedge pressure, systemic vascular resistance, and cardiac index were significantly changed from 1 to 12 hours after alacepril administration. Plasma ANP and BNP decreased significantly after alacepril was given to the CHF group: neither concentration changed in the control group. In the CHF group plasma ANP was significantly lower between 1 and 6 hours and was highly significantly correlated with pulmonary capillary wedge pressure. Plasma BNP, however, was significantly lower between 6 and 24 hours after alacepril and was not correlated with pulmonary capillary wedge pressure.

Conclusions-The response of plasma BNP after alacepril administration occurred later and lasted longer than the plasma ANP response. This may indicate that the mechanisms of synthesis, secretion, or degradation of the two peptides are different.

(Br Heart f 1994;72:528-533)

A Type or atrial natriuretic peptide (ANP) has a wide range of potent biological effects including natriuresis, vasodilatation, and inhibition of renin and aldosterone secretion ${ }^{1-4}$ and it has an important role in the homoeostasis of body fluids and blood pressure. The secretion of ANP is regulated mainly by atrial stretching and ANP is secreted not only by the coronary sinus but also directly into the atrial cavities. ${ }^{5}$ Plasma concentrations of ANP are higher in patients with congestive heart failure (CHF) ${ }^{6-10}$

B Type or brain natriuretic peptide (BNP) was first isolated from a porcine brain, ${ }^{11}$ and subsequently from the hearts of pigs ${ }^{12}$ and rats. ${ }^{13-15}$ BNP belongs to the same family of peptides as ANP and like ANP has strong vasodilating and natriuretic actions. ${ }^{16-18} \mathrm{We}$ isolated human BNP from human atrium, determined its amino acid sequence, ${ }^{19}$ and established a specific radioimmunoassay for human BNP by developing a monoclonal antibody against it. ${ }^{20} \mathrm{We}$ showed that BNP is a novel cardiac hormone secreted mainly from the ventricle ${ }^{2021}$ and that plasma BNP is much increased in patients with $\mathrm{CHF}$ and those with acute myocardial infarction. ${ }^{20} 22$

In patients with CHF the reninangiotensin-aldosterone, arginine vasopressin, and sympathetic nervous systems are activated. ${ }^{23-26}$ Though the heightened activities of these vasoconstrictive agents help to maintain the perfusion pressure to vital organs, they can, by increasing both preload and afterload, ultimately contribute to the deterioration of cardiac function and high mortality. ${ }^{27} 28$ Though both ANP and BNP, vasodilating peptides, are secreted in large amounts in patients with $\mathrm{CHF}$, the concentrations attained in these patients may not be sufficient to improve left ventricular function: intravenous infusion of both ANP and BNP improves left ventricular function by reducing both preload and afterload. ${ }^{29} 30$

There are many reports that treatment with angiotensin-converting enzyme inhibitors is beneficial in patients with CHF. 232728 31-34 Because atrial stretching is an important regulator of ANP release, it might be anticipated that angiotensin-converting enzyme inhibitors, because of the reduced preload, can induce a decrease in plasma ANP. However, there is no consensus on the effect of angiotensin-converting enzyme inhibitors on ANP release. ${ }^{35}{ }^{36}$ Furthermore, there are few reports on the response of plasma BNP to the administration of ACE inhibitors in patients with CHF. In this study we examined the short term haemodynamic and hormonal 
responses, especially of ANP and BNP to alacepril (an ACE inhibitor) given by mouth to patients with $\mathrm{CHF}$.

\section{Patients and methods \\ PATIENTS}

We studied 12 patients with CHF ( 7 men and 5 women; aged 43-72 (mean 54)) and 11 controls (6 men and 5 women; aged 41-68 (mean 51)). The cause of CHF was dilated cardiomyopathy in eight patients, old myocardial infarction in three patients, and mitral regurgitation in one patient. Nine patients were in New York Heart Association class III and three were in class IV. The controls had complained of chest pain, but no cardiac disease was apparent on a coronary arteriogram and left ventriculogram.

Written informed consent was obtained from each patient and his or her family. This study protocol accords with the guidelines of the ethics committees of our hospitals.

\section{STUDY PROTOCOL}

Figure 1 shows the study protocol. A SwanGanz catheter (Goodtec, USA) was inserted a day before the study and the patients were kept in bed overnight. The study patients did not receive any drugs for at least 24 hours before the procedure. Two serial baseline measurements were obtained in each patient 15 minutes apart and when haemodynamic variables were stable the patients were given alacepril ( $37.5 \mathrm{mg}$ by mouth).

\section{Haemodynamic measurements}

Pulmonary capillary wedge pressure, pulmonary arterial pressure, right atrial pressure, and systemic blood pressure were measured 15 minutes before and immediately before alacepril was given by mouth; and 1, 2, 3, 4, $6,8,12$, and 24 hours after alacepril administration. Cardiac output was measured in triplicate by the thermodilution technique at the same time as the pressure measurements. The heart rate was monitored continuously by the electrocardiogram (lead II). Cardiac index and systemic vascular resistance were calculated by standard formulas.

\section{Blood sampling}

Blood samples were taken from the pulmonary artery through a Swan-Ganz catheter at the same time as the pressure was measured. Blood samples for the measurement of plasma renin activity and plasma concentra-

Alacepril $(37.5 \mathrm{mg}$ ) by mouth

\begin{tabular}{|c|c|c|c|c|}
\hline Time course & $n+1234$ & 6 & 12 & 24 \\
\hline re measurements & 000000 & $\circ$ & $\circ$ & \\
\hline $\begin{array}{l}\text { tput } \\
\text { pling }\end{array}$ & $\begin{array}{l}000000 \\
000000\end{array}$ & & $\stackrel{\circ}{\circ}$ & 。 \\
\hline
\end{tabular}

Figure 1 Study protocol. Haemodynamic measurements included pulmonary arterial pressure, pulmonary capillary wedge pressure, right atrial pressure, and systemic arterial pressure. tions of aldosterone, catecholamine, ANP, and BNP were transferred to chilled disposable tubes containing aprotinin (1000 kallikrein inactivator units $/ \mathrm{ml}$ ) and ethylenediaminetetraacetic acid $(1 \mathrm{mg} / \mathrm{ml})$. All the blood samples were immediately placed on ice and promptly centrifuged at $4^{\circ} \mathrm{C}$. Aliquots of plasma were immediately stored at $-80^{\circ} \mathrm{C}$ until the assay.

\section{Measurement of plasma hormones}

The plasma concentration of ANP was measured by a specific radioimmunoassay for $a$ human ANP as reported elsewhere. ${ }^{37}$ This radioimmunoassay recognises a carboxyterminal sequence of ANP and the minimum limit of detection is $1 \mathrm{pg} /$ tube. The intra- and inter assay coefficients of variation were $7 \cdot 2 \%$ and $7 \cdot 8 \%$ respectively. The cross reactivity with human BNP and $\mathrm{C}$ type natriuretic peptide was less than $0.01 \%$ on a molar basis. Plasma BNP was measured by a specific radioimmunoassay with a monoclonal antibody that recognised the ring structure of human BNP. ${ }^{20}$ The limit of detection was $1 \mathrm{pg} /$ tube. The intra assay and inter assay coefficients of variation were $8.4 \%$ and $6.4 \%$ respectively. The cross reactivity with $a$ human ANP was less than $0.01 \%$ and with $C$ type natriuretic peptide it was less than $1 \%$ on a molar basis. Plasma renin activity and plasma aldosterone concentration were measured with commercial kits-renin radioimmunoassay beads (Dainabot, Tokyo, Japan) and an aldosterone radioimmunoassay kit II (Dainabot, Tokyo, Japan) respectively. Plasma noradrenaline was measured by high performance liquid chromatography combined with the trihydroxyindole fluorometric procedure (HLC8030 Tosoh, Tokyo, Japan).

\section{STATISTICAL ANALYSIS}

All values were expressed as mean (1SE). We used one way analysis of variance for repeated measures with subsequent Dunnett's test for within group comparisons. ${ }^{38}$ Haemodynamic variables and hormone concentrations in the control and CHF groups were compared by unpaired $t$ testing. A $P$ value $<0.05$ was regarded as statistically significant.

\section{Results}

HAEMODYNAMIC STUDY

Figure 2 shows the results of the haemodynamic measurements. Pulmonary capillary wedge pressure decreased significantly from 1 hour after the administration of alacepril in both the control and CHF groups, and the lowest level was reached 3 hours after administration of alacepril in both the control and CHF groups. In both groups pulmonary capillary wedge pressure remained significantly reduced up to 12 hours after alacepril. At each time during the study there was a significant difference in pulmonary capillary wedge pressure between the control and CHF groups.

Cardiac index increased significantly from 1 hour after the administration in the CHF group and a maximum was reached 2 hours 

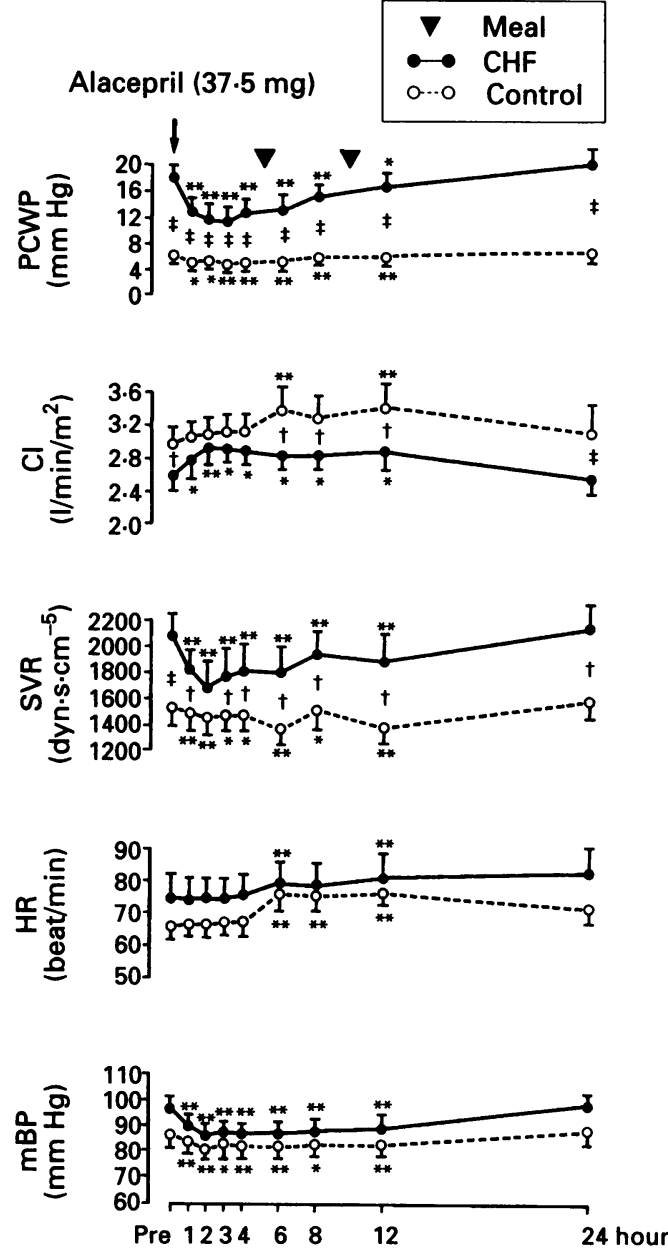

Figure 2 Serial responses of pulmonary capillary wedge pressure (PCWP), cardiac index (CI), systemic vascular resistance (SVR), heart rate (HR), mean systemic arterial pressure (MAP) during the study period in the congestive heart failure (CHF) and control groups.

Pre, pre-administration. ${ }^{\star} P<0.05,{ }^{\star} * P<0.01$ compared with pre-administration value. $\dagger P<0.05$, $\ddagger P<0.01$ control $v C H F$.

after the administration of alacepril. A significant increase persisted up to 12 hours after the administration of alacepril to the CHF group. In the controls, however, there was no significant increase in cardiac index except at 6 and 12 hours. Cardiac index was significantly lower in the CHF group than in the control group before alacepril was given and $6,8,12$, and 24 hours after it was given.

In both groups systemic vascular resistance was significantly lower 1 hour after alacepril. It was lowest in the CHF group 2 hours after alacepril and in the control group at 6 hours. A significant decrease persisted at 12 hours in both groups. There was a significant difference in systemic vascular resistance between the control and $\mathrm{CHF}$ groups at each time except 2 hours after alacepril was given.

Heart rate did not change during the first 4 hours in either group and increased significantly at 6 and 12 hours in the CHF group and at 6,8 , and 12 hours in the control group. Heart rate tended to be higher in the CHF group than in the control group, but none of the differences in heart rate between the two groups during the study period was significant.
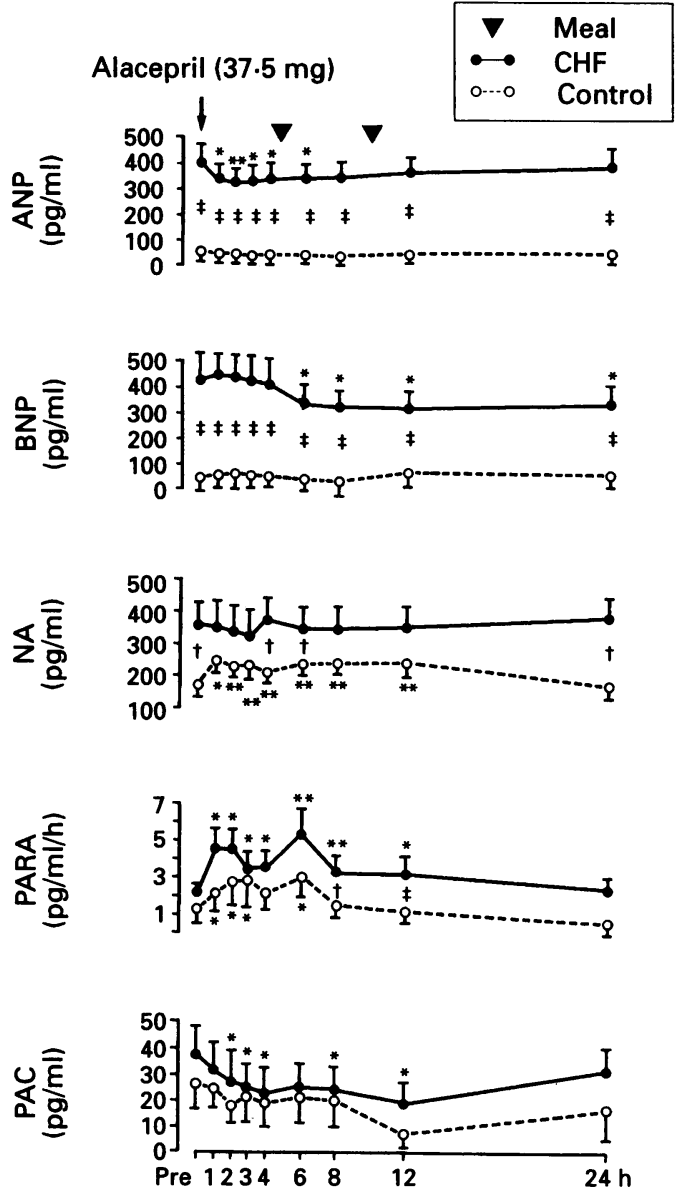

Figure 3 Serial responses of plasma concentrations of type $A$ natriuretic peptide (ANP), type $B$ natriuretic peptide $(B N P)$, noradrenaline (NE), and aldosterone (PAC) and response of plasma renin activity in the congestive heart failure (CHF) and control groups.

Pre, pre-administration ${ }^{\star} P<0.05,{ }^{*} P<0.01$ compared with pre-administration value. $\dagger P<0.05, \ddagger P<0.01$ control $v$ CHF.

Mean blood pressure decreased significantly from 1 hour after administration in both the control and CHF groups, and was lowest at 2 hours in both the control and CHF groups. The decrease was still significant 12 hours after alacepril in both groups. Mean blood pressure tended to be higher in the CHF group than in the control group, but none of the differences between the two groups was significant.

\section{HORMONAL RESPONSES}

Figure 3 shows the result of the hormonal responses. Plasma ANP decreased significantly from 1 hour after the administration in the CHF group, and was lowest 2 hours after oral alacepril. In the CHF group plasma ANP remained significantly lower 6 hours after the administration. In the controls, however, plasma ANP did not change in the 24 hours of the study. Throughout the study plasma ANP was significantly higher in the CHF group than in the controls.

Plasma BNP did not change during the first 4 hours after alacepril. In the CHF group it began to decrease significantly from 6 hours 


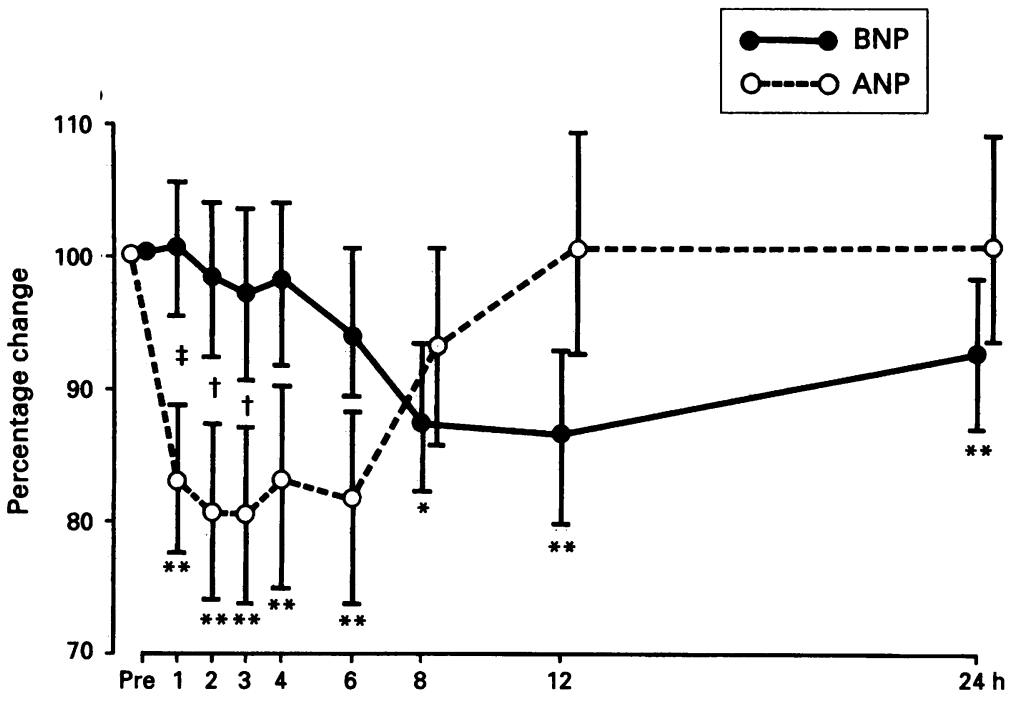

Figure 4 Percentage changes in plasma ANP and BNP in patients with congestive heart failure (CHF).

Pre, pre-administration (100\%). ${ }^{*} P<0.05,{ }^{*} P<0.01$ compared with values at time 0 . $\dagger P<0.05, \ddagger P<0.01$ control $v$ CHF.
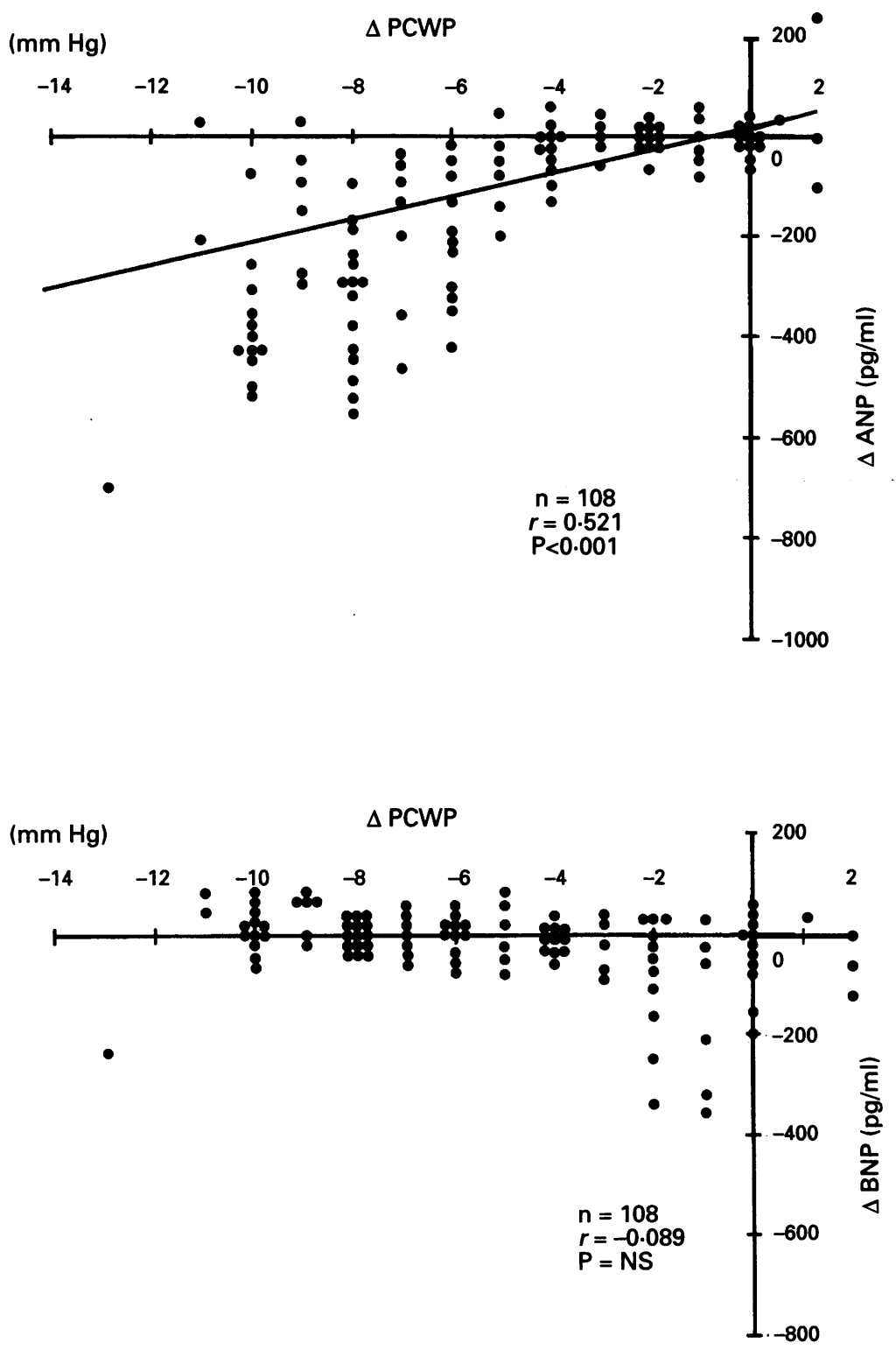

Figure 5 Correlation of $\triangle P C W P$ with $\triangle A N P$ (upper) and $\triangle B N P$ (bottom) in the congestive heart failure (CHF) group. There is a significant linear correlation between $\triangle P C W P$ and $\triangle A N P$, but not between $\triangle P C W P$ and $\triangle B N P$.

$\triangle P C W P$, change in pulmonary capillary wedge pressure compared with the pre-

administration value. $\triangle A N P$, change in plasma $A N P$ compared with the pre-administration value. $\triangle B N P$, change in plasma $B N P$ compared with the pre-administration value. and reached the lowest value 12 hours after administration: a significant decrease in plasma BNP persisted at 24 hours. In the controls, however, there was no change in plasma BNP in the 24 hours after alacepril. Throughout the study period plasma BNP was significantly higher in the CHF group than in the control group.

Plasma noradrenaline did not change significantly after alacepril was given to the $\mathrm{CHF}$ group. In the controls, however, it increased significantly from 1 hour, when it reached a peak. Plasma noradrenaline was still significantly raised at 12 hours in the control group. Plasma noradrenaline in the CHF group was significantly higher before administration and 4,8 , and 12 hours after administration of alacepril than in the control group.

In both groups plasma renin activity increased significantly after alacepril and reached a peak at 6 hours. It remained significantly increased at 12 hours in the CHF group and at 6 hours in the controls. Plasma renin activity was significantly higher at 8 and 12 hours in the CHF group than in the controls. Plasma aldosterone was significantly lower at $2,3,4,8$, and 12 hours after alacepril in the CHF group but did not change significantly in the control group. It tended to be higher in the CHF group than in the control group.

Figure 4 shows the percentage change in plasma ANP and BNP after alacepril. Plasma ANP was significantly reduced from 1 hour to 6 hours after alacepril and plasma BNP was significantly reduced at 8,12 , and 24 hours. The percentage reduction in ANP at 1, 2, and 3 hours after alacepril was significantly greater than the reduction in BNP.

\section{Correlation between pulmonary capillary wedge pressure and plasma ANP and} BNP

Figure 5 shows the correlation between the change in pulmonary capillary wedge pressure from the value before alacepril ( $\triangle$ PCWP) and the change in plasma ANP or BNP from the value before alacepril ( $\triangle$ ANP or $\triangle \mathrm{BNP}$ ). There was a significant correlation between $\triangle$ PCWP and $\triangle$ ANP $(n=108, r=0.521$, $\mathrm{P}<0.001$ ) but there was no correlation between $\triangle$ PCWP and $\triangle \mathrm{BNP}(\mathrm{n}=108$, $r=-0.089, \mathrm{P}=\mathrm{NS}$ ).

\section{Discussion}

HAEMODYNAMIC RESPONSES TO ALACEPRIL

It is widely accepted that vasoconstrictor systems such as the renin-angiotensinaldosterone system, sympathetic nervous system, and vasopressin are excessively activated in patients with CHF. ${ }^{23-26}$ Many studies show the efficacy of angiotensin-converting enzyme inhibitors in the treatment of CHF. ${ }^{23272831-34}$ We examined the haemodynamic and hormonal responses to alacepril, an angiotensinconverting enzyme inhibitor, in patients with CHF.

Alacepril is a sulphhydryl-containing prodrug of captopril that is converted into 
captopril via an intermediate desacetyl-alacepril chiefly in the intestine, liver, and to a lesser extent the kidneys. ${ }^{39}$ Alacepril has a prolonged duration of action and reduces blood pressure in patients with hypertension. ${ }^{40}$

Alacepril reduced pulmonary capillary wedge pressure and systemic vascular resistance and increased cardiac index, indicating that it relieved both preload and afterload, and improved left ventricular function in patients with CHF. This accords with the results of studies of other ACE inhibitors. ${ }^{31-34}$ Treatment with alacepril maintained a reduction of both preload and afterload for as long as a half day. This result clearly indicates that alacepril is useful for the treatment of CHF.

RESPONSES OF NORADRENALINE, RENIN, AND ALDOSTERONE TO ALACEPRIL

Some short-term trials of enalapril and captopril showed a significant reduction in plasma noradrenaline ${ }^{41}{ }^{42}$; others did not. ${ }^{3643}$ In the present study we found that plasma noradrenaline increased after alacepril was given by mouth to the controls, probably in response to the reduction of systemic arterial pressure. In the CHF group, however, noradrenaline concentrations did not change, even when systemic arterial pressure decreased. This is probably because the arterial baroreflex was reduced in patients with CHF. ${ }^{44} 45$

Plasma renin activity was increased after alacepril administration in the controls and the CHF group, and plasma aldosterone concentration tended to decrease in both groups, which is regarded as indirect evidence of a decrease in angiotensin II activity. These results accord studies of other ACE inhibitors. $^{32} 33$

\section{RESPONSES OF ANP AND BNP TO ALACEPRIL}

Plasma ANP decreased from 1 hour after alacepril administration, and remained significantly lower up to 6 hours after alacepril was given by mouth. The secretion of ANP is mainly regulated by stretching of the atria and its plasma concentrations are increased in patients with CHF. ${ }^{10}$ ANP is also secreted by the ventricles in patients with CHF. ${ }^{104647}$ Thus in the present study reduced atrial overload is thought to have contributed to the decreased plasma concentration of ANP. This suggestion accords with the significant correlation between the degree of change of the plasma ANP and that of pulmonary capillary wedge pressure.

A novel finding in the present study is the different responses in plasma ANP and BNP after alacepril administration. BNP was first isolated from a porcine brain, ${ }^{11}$ and subsequently from the hearts of pigs ${ }^{12}$ and rats. ${ }^{13-15}$ BNP belongs to the same peptide family as ANP, and like ANP may be involved in the regulation of blood pressure and fluid volume. ${ }^{16-18}$ We showed that BNP is a novel cardiac hormone secreted mainly by the ventricle, ${ }^{2021}$ and that its plasma concentration is greatly increased in patients with CHF and those with acute myocardial infarction. ${ }^{20} 22$ None the less the secretion patterns of ANP and BNP vary with underlying cardiac disorders in CHF. ${ }^{48}$ Plasma BNP showed a much delayed and sustained response to alacepril compared with that of ANP, and plasma BNP was reduced for up to 24 hours, when pulmonary capillary wedge pressure had already returned to the pre-administration value. There was no significant correlation between the degree of change in plasma BNP and that of pulmonary capillary wedge pressure, suggesting that the secretion of BNP is not regulated by atrial pressure.

We have reported that clearance of BNP from circulation is slower than that of ANP. ${ }^{20}$ This may have contributed to the delayed reduction of plasma BNP. However, because $\mathrm{BNP}$ has a half life of a few minutes, ${ }^{20}$ the increase in plasma BNP that lasts several hours after alacepril can not be explained by this mechanism.

ANP is stored in granules in atrial cardiocytes (regulated pathway) $)^{1-421}$ and is secreted mainly in response to stretching of the atrial wall. This explains the rapid decrease in plasma ANP when pulmonary capillary wedge pressure falls. We found, however, that BNP was secreted without being stored after synthesis in the ventricle, as evidenced by increased synthesis of messenger RNA in response to stimulus (constitutive pathway). ${ }^{21}$ In the present study the synthesis of BNP in ventricles may have continued for several hours, even after the reduction of ventricular overload. The precise mechanism of the slow fall in plasma BNP remains uncertain. Other factors also may be involved in the mechanism.

In conclusion, plasma concentrations of both ANP and BNP decreased significantly after alacepril, an ACE inhibitor, was given by mouth. Plasma BNP showed a much delayed and prolonged response compared with that of ANP, which decreased rapidly in parallel with the reduction of pulmonary capillary wedge pressure. This difference may be accounted for by different mechanisms of synthesis, secretion, and degradation for ANP and BNP. The study also showed that the administration of alacepril, an ACE inhibitor, improved left ventricular function by reducing both preload and afterload and is useful for the treatment of $\mathrm{CHF}$.

This study was supported in part by a grant from Scientific Research B 03454257 from the Ministry of Education and Culture, Tokyo, Japan and a grant from Smoking Research Foundation, Tokyo, Japan.

1 de Bold AJ, Borenstein HB, Veress AT, Sonnenberg H. A rapid and important natriuretic response to intravenous injection of atrial myocardial extracts in rats. Life Sci 1981;28:89-94.

2 Laragh JH. Atrial natriuretic hormone, the renin aldosterone axis, and blood pressure-electrolyte homeostasis. $N$ Engl f Med 1985;313:1330-40.

3 Needleman P, Greenwald JE. Atriopeptin: A cardiac hormone intimately involved in fluid, electrolyte, and blood-pressure homeostasis. $N$ Engl f Med 1986;314: 828-34.

4 Ballermann BJ, Brenner BM. Role of atrial peptides in body fluid homeostasis. Circ Res 1986;58:619-30.

5 Obata K, Yasue H, Okumura K, Matsuyama K, Ogawa H, Kurose M, et al. Atrial natriuretic polypeptide is removed by the lungs and released into the left atrium as well as the right atrium in humans. $7 \mathrm{Am}$ Coll Cardiol 1990;15:1537-43. 
6 Burnett JC Jr, Kao PC, Hu DC, Heser DW, Heublein D, Granger JP, et al. Atrial natriuretic peptide elevation in congestive heart failure in the human. Science 1986;231:1145-7.

7 Cody RJ, Atlas SA, Laragh JH, Kubo SH, Covit AB, Ryman KS, et al. Atrial natriuretic factor in normal sub-
jects and heart failure patients. $\mathcal{F}$ Clin Invest 1986; 78:1362-74.

8 Raine AEG, Erne P, Bürgisser E, Müller FB, Bolli P, Burkart $F$, et al. Atrial natriuretic peptide and atrial pressure in patients with congestive heart failure. $N$ Engl $f$ Med 1986;315:533-7.

9 Sugawara A, Nakao $\dot{K}$, Morii N, Yamada T, Itoh H, Shiono S, et al. Synthesis of atrial natriuretic polypeptide in human failing hearts. $\mathcal{F}$ Clin Invest 1988;81:1962-70.

10 Yasue $H$, Obata $K$, Okumura $K$, Kurose M, Ogawa $H$, Matsuyama $\mathrm{K}$, et al. Increased secretion of atrial natriuretic polypeptide from the left ventricle in patients with uretic polypeptide from the left ventricle in patients with
dilated cardiomyopathy. $₹$ Clin Invest 1989;83:46-51.

11 Sudoh T, Kangawa K, Minamino N, Matsuo H. A new natriuretic peptide in porcine brain. Nature 1988;332: 78-81.

12 Saito Y, Nakao K, Itoh H, Yamada T, Mukoyama M, Arai $\mathrm{H}$, et al. Brain natriuretic peptide is a novel cardiac hormone. Biochem Biophys Res Commun 1989;158:360-8.

13 Itoh H, Nakao K, Kambayashi Y, Hosoda K, Saito Y, Yamada $\mathrm{T}$, et al. Occurrence of a novel cardiac natriuretic peptide in rats. Biochem Biophys Res Commun 1989;161:732-9.

14 Ogawa $Y$, Nakao $K$, Mukoyama $M$, Shirakami G, Itoh H, Hosoda $\mathrm{K}$, et al. Rat brain natriuretic peptide-Tissue distribution and molecular form. Endocrinology distribution and

15 Nakao K, Itoh H, Kambayashi Y, Hosoda K, Saito Y, Yamada $\mathrm{T}$, et al. Rat brain natriuretic peptide-Isolation from rat heart and tissue distribution. Hypertension 1990;15:774-8.

16 Itoh H, Nakao K, Yamada T, Shirakami G, Kangawa K, Minamino N, et al. Antidipsogenic action of a novel peptide "brain natriuretic peptide" in rats. Eur $\mathcal{F}$ Pharmacol 1988;150:193-6.

17 Yamada T, Nakao K, Itoh H, Shirakami G, Kangawa K, Minamino $\mathrm{M}$, et al. Intracerebroventricular injection of brain natriuretic peptide inhibits vasopressin secretion in conscious rats. Neurosci Lett 1988;95:223-8.

18 Shirakami G, Nakao K, Yamada T, Itoh $H$, Mori $K$, Kangawa $\mathrm{K}$, et al. Inhibitory effect of brain natriuretic Kangawa $\mathbf{K}$, et al. Inhibitory effect of brain natriuretic peptide on central angiotensin II-stimulated pressor

19 Kambayashi Y, Nakao K, Mukoyama M, Saito Y, Ogawa $\mathrm{Y}$, Shiono $\mathrm{S}$, et al. Isolation and sequence determination of human brain natriuretic peptide in human atrium. FEBS Lett 1990;259:341-5.

20 Mukoyama M, Nakao K, Saito Y, Ogawa Y, Hosoda K, Suga $\mathrm{S}$, et al. Brain natriuretic peptide (BNP) as a novel cardiac hormone in humans-Evidence for an exquisite dual natriuretic peptide system, atrial natriuretic peptide and brain natriuretic peptide. $\mathcal{F}$ Clin Invest 1991;87: 1402-12.

21 Ogawa $H$, Nakao K, Mukoyama M, Hosoda K, Shirakami $\mathrm{G}$, Arai $\mathrm{H}$, et al. Natriuretic peptides as cardiac hormones in normotensive and spontaneously hypertensive mones in normotensive and spontaneously hypertensive rats-The ventricle is a major site of synthesis and secre-
tion of brain natriuretic peptide. Circ Res 1991;69: tion of $491-500$.

22 Morita E, Yasue H, Yoshimura M, Ogawa H, Jougasaki $M$, Matsumura $T$, et al. Increased plasma levels of brain natriuretic peptide in patients with acute myocardial infarction. Circulation 1993;88:82-91.

23 Cohn JN, Johnson G, Ziesche S, Cobb F, Francis G, Tristani F, et al. A comparison of enalapril with hydralazine-isosorbide dinitrate in the treatment of chronic congestive heart failure. $N$ Engl $\%$ Med 1991;325: 303-10.

24 Levine TB, Francis GS, Goldsmith SR, Simon AB, Cohn IN. Activity of the sympathetic nervous system and N. Activity of the sympathetic nervous system and renin-angiotensin system assessed by plasma hormonal levels and their relationship to hemodynamic abnormalities in cong

25 Curtiss C, Cohn JN, Vrobel T, Franciosa JA. Role of the renin-angiotensin system in the systemic vasoconstriction of chronic congestive heart failure. Circulation 1978;58:763-70.

26 Szatalowicz VL, Arnold PE, Chaimovitz L, Bichet D, Bert $T$, Schrier RW. Radioimmunoassay of plasma arginine vasopressin in hyponatremic patients with congestive heart failure. N Engl f Med 1981;305:263-6.
27 The SOLVD investigators. Effects of enalapril on survival in patients with reduced ejection fraction and congestive heart failure. N Engl $₹$ Med 1991;325:293-302.

28 The CONSENSUS Trial Study Group. Effects of enalapril on mortality in severe congestive heart failure. Results of the Cooperative North Scandinavian Enalapril Survival Study (CONSENSUS). N Engl $₹$ Med 1987;316:1429-35.

29 Saito $Y$, Nakao K, Nishimura K, Sugawara A, Okumura $\mathrm{K}$, Obata $\mathrm{K}$, et al. Clinical application of atrial natriuretic polypeptide in patients with congestive heart failure: beneficial effects on left ventricular function. Circulation 1987;76:115-24.

30 Yoshimura M, Yasue H, Morita E, Sakaino N, Jougasaki $M$, Kurose $M$, et al. Hemodynamic, renal and hormonal responses to brain natriuretic peptide infusion in patients with congestive heart failure. Circulation 1991; 84:1581-8.

31 The captopril multicenter research group. A placebo-controlled trial captopril in refractory chronic congestive trolled trial captopril in refractory chronic con

32 Dzau VJ, Colucci WS, Williams GH, Curfman G, Meggs L, Hollenberg NK. Sustained effectiveness of converting-enzyme inhibitor in patients with severe congestive heart failure. N Engl ₹ Med 1980;302:1373-9.

33 DiCarlo L, Chatterjee K, Parmley WW, Swedberg K, Atherton B, Curran D. Enalapril, a new angiotensin converting enzyme inhibitor in chronic heart failure: Acute and chronic hemodynamic evaluations. $f \mathrm{Am} \mathrm{Coll}$ Cardiol 1983;2:865-71.

34 Giles TD, Katz R, Sullivan JM. Short- and long-acting angiotensin-converting enzyme inhibitors: $A$ randomized trial of lisinopril versus captopril in the treatment of contrial of lisinopril versus captopril in the treatment of con-

35 Richards AM, Rao G, Espiner EA, Yandle T. Interaction of angiotensin converting enzyme inhibitor and atrial natriuretic factor. Hypertension 1989;13:193-9.

36 Kubo SH. Neurohormonal activation and the response to converting enzyme inhibitors in congestive heart failure. Circulation 1990;81 (suppl III): 107-14.

37 Nakao K, Sugawara A, Morii N, Sakamoto M, Sudo $M$, Sonoda J, et al. Radioimmunoassay for $a$-human and rat atrial natriuretic polypeptide. Biochem Biophys Res Commun 1984;124:815-21.

$38 \mathrm{Zar}$ JH. Biostatistical analysis, ed 2. New Jersey: Prentice

39 Matsumoto K, Miyazaki H, Fujii T, Yoshida K, Amejima H, Hashimoto M. Deposition and metabolism of the novel antihypertensive agent alacepril in rats. the novel antihypertensive agent
Arzneimittelforschung 1986;36:40-6.

40 Shionoiri H, Miyazaki N, Yasuda G, Miyakawa T, Takasaki I, Kaneko Y. Pharmacokinetics and antihypertensive effects of single and consecutive dosing of alacepril (DU-1219) in patients with severe hypertension. Curr Therap Res 1985;38:537-47.

41 Riegger GAJ, Kochsiek K. Vasopressin, renin and norepinephrine levels before and after captopril administration in patients with congestive heart failure due to idiopathic dilated cardiomyopathy. Am ₹ Cardiol 1986;58:300-3.

42 Mattauer B, Rouleau JL, Bichet D, Kortas C, Manzini C, et al. Different long term intrarenal and neurohormonal effects of captopril and prazosin in patients with chronic effects of captopril and prazosin in patients with chronic
congestive heart failure: Importance of initial plasma congestive heart failure: Importance of in

43 Levine TB, Olivali MJ, Garberg V, Sharkey SW, Cohn JN. Hemodynamic and clinical response to enalapril, a longacting converting enzyme inhibitor, in patients with congestive heart failure. Circulation 1984;69:548-53.

44 Amorim DS, Dargie HJ, Heer K, Brown M, Jenner D, Olsen EGJ, et al. Is there autonomic impairment in con-

gestive (dilated) cardiomyopathy? Lancet 1981;1:525-7. Impairment of autonomically mediated heart rate control in patients with cardiac dysfunction. Cir Res 1975; 36:571-8.

46 Saito $Y$, Nakao $K$, Arai $H$, Nishimura $K$, Okumura $K$, Obata $\mathrm{K}$, et al. Augmented expression of atrial natriObata $\mathrm{K}$, et al. Augmented expression of atrial natriuretic polypeptide gene in ventricle

47 Edwards BS, Ackermann DM, Lee ME, Reeder GS, Wold LE, Burnett JC Jr. Identification of atrial natriuretic factor within ventricular tissue in hamsters and humans with congestive heart failure. $\mathcal{F}$ Clin Invest 1988;81:82-6.

48 Yoshimura M, Yasue H, Okumura K, Ogawa H, Jougasak $\mathbf{M}$, Mukoyama $\mathbf{M}$, et al. Different secretion patterns of atrial natriuretic peptide and brain natriuretic peptide in patients with congestive heart failure. Circulation 1993;87:464-9. 